\title{
Enhanced aquathermolysis of extra-heavy oil by application of transition metal oxides submicro-particles in relation to steam injection processes
}

\author{
Xian Zhang ${ }^{1} \mathbb{D} \cdot$ Hongchang Che $^{2} \cdot$ Yongjian Liu ${ }^{1}$
}

Received: 25 March 2021 / Accepted: 6 September 2021 / Published online: 16 September 2021

(c) The Author(s) 2021

\begin{abstract}
In order to investigate the catalytic effects of transition metal oxides submicro-particles on aquathermolysis of Liaohe extraheavy crude oil, the catalysts $\mathrm{NiO}, \alpha \cdot \mathrm{Fe}_{2} \mathrm{O}_{3}$ and $\mathrm{Co}_{3} \mathrm{O}_{4}$ are used and evaluated during the experiments. The optimum mass fraction of the catalyst and water was determined to be $5.0 \mathrm{wt} \%$ and $30 \mathrm{wt} \%$, respectively. The optimum reaction time for aquathermolysis was $24 \mathrm{~h}$, and the optimum reaction temperature was $240{ }^{\circ} \mathrm{C}$. The analysis results showed the heavy oil was upgraded dramatically by addition of the catalysts based upon viscosity reduction, saturate/aromatics/resins/asphaltenes analyses, elemental analysis, Fourier transform infrared spectroscopy and gas chromatography. All results show the heavy oil is in situ updated dramatically by catalytic aquathermolysis under the optimum operating conditions. A five-lump model is proposed for estimating kinetic parameters of aquathermolysis and agrees well with the experimental data.
\end{abstract}

Keywords Extra-heavy oil $\cdot$ Aquathermolysis $\cdot$ Catalyst $\cdot$ Viscosity reduction $\cdot$ Five-lump model

\section{Introduction}

Heavy crude oils represent a significant share of the total oil reserves, and steam injection is the most commonly used method for recovering heavy crude oils (Santos et al. 2014). In the 1980s, the researchers discovered chemical reactions called aquathermolysis leading to in situ upgrading of heavy oils during steam injection processes (Clark and Hyne 1984). Smaller fragments are produced from organosulphur compounds and subsequently take part in a series of reactions during aquathermolysis, resulting in generation of smaller components such as $\mathrm{H}_{2} \mathrm{~S}, \mathrm{CO}_{2}, \mathrm{CH}_{4}$ and $\mathrm{H}_{2}$. Increases in light components and decreases in heavy components and significant viscosity reduction of heavy crude oils are observed after aquathermolysis in most of the literature (Kapadia et al. 2015). It has been proven that transition metals exert beneficial effects on the aquathermolysis of heavy

Xian Zhang

zhangxianer@163.com

1 Petroleum Engineering Institute, Northeast Petroleum University, Daqing 163318, People's Republic of China

2 PetroChina International Middle East, Beijing 124000, People's Republic of China oils (Li et al. 2018a, b; Muraza 2015). Effects of nickel, iron and cobalt-based nanocatalysts on viscosity reduction of heavy oils were reported by Iskandar (2016), and the presence of surfactant ( $20 \mathrm{wt} \%$ ethylene glycol) shows no improvements on the catalytic performance. $\mathrm{CuO}$ nanoparticles were in situ prepared and showed $94.6 \%$ reduction in viscosity of Shengli heavy oil (Chen 2019). Li (2018) reported that ferric oleate was more efficient for heavy oil cracking than $\mathrm{Co}$ and $\mathrm{Ni}$ oleates in the aquathermolysis of Shengli heavy oils. Influences of hydrogen donors and formation minerals on the aquathermolysis of heavy oils have also been investigated by several authors in order to identify the additional chemicals apart from the transition metals for enhancing the reaction (Zhang et al. 2010; Zhao et al. 2011).

Perez-Perez et al. (2011) constructed a kinetic model to mimic $\mathrm{H}_{2} \mathrm{~S}$ and $\mathrm{CO}_{2}$ emissions during aquathermolysis of Athabasca bitumen. A total of thirteen components are included in the model, and the prediction of gas emissions is in line with the results reported from field. However, some weaknesses of the kinetic models were identified by the authors, and the application of the model was limited to the idealized Athabasca bitumen. Kapadia et al (2012) proposed the aquathermolysis reaction scheme using an exponential decay model. The model was composed of seven reactions that represent production of non-condensable gases from Athabasca 
bitumen under steam injection conditions. The water-gas shift reaction was taken into consideration for the production of $\mathrm{CO}_{2}$ and $\mathrm{H}_{2}$ from further reaction by $\mathrm{CO}$ and $\mathrm{H}_{2} \mathrm{O}$. The reaction model was applicable to steam-based bitumen recovery processes. The results showed good agreement for bitumen conversion and evolved gases volumes. Huang et al (2017) proposed a modified model considering both heavy components and gas emissions. The numerical simulation from the model indicated a good match with experimental and field data and revealed reduction in near-bore water saturation. This model only considers the conversion of resins and asphaltenes into smaller fragments, while does not reflect the conversion between different components. Further studies are needed since the properties of heavy crudes vary and kinetics is not representative.

In this paper, transition metal oxides submicro-particles of $\mathrm{NiO}, \alpha \cdot \mathrm{Fe}_{2} \mathrm{O}_{3}$ and $\mathrm{Co}_{3} \mathrm{O}_{4}$ are used during aquathermolysis of Liaohe extra-heavy crude oil in order to investigate the effects of the catalysts and determine the optimum operating parameters. Due to the fact that particle size distribution is broad and there are some particles falling into nanocategory, a significantly different behavior of submicro-particles versus the published nanoparticles studies is not expected (Anderson et al 2013; Galukhin et al 2017; Lakhova et al. 2017). A five-lump model is proposed to estimate the kinetic parameters of the aquathermolysis, considering the conversions among different pseudo-components.

\section{Materials and methods}

\section{Materials}

The heavy crude oil sample was obtained from Liaohe Oilfield in China. The Liaohe heavy crude oils typically have high resin content in composition, usually greater than $30 \mathrm{wt} \%$ (Li et al. 2018a, b; Yi et al. 2009). Different from most of the other heavy oils around the world, they often present relatively high viscosity, low specific gravity, and low contents in sulfur and nickel. For saturates/aromatics/resins/ asphaltenes (SARA) analysis, analytically pure chemicals such as methenyl chloride, $n$-hexane, methanol, methylene chloride, absolute ethyl alcohol, activated aluminum oxide and other additives were purchased from Haerbin Chemical Engineering Plant. The transition metal oxides $\mathrm{NiO}, \alpha \cdot \mathrm{Fe}_{2} \mathrm{O}_{3}$ and $\mathrm{Co}_{3} \mathrm{O}_{4}$ (submicro-particles) were purchased from Shenyang Reagent Plant.

\section{Experimental methods}

\section{Analysis of the properties of the heavy oils and the catalysts}

The viscosity of the dehydrated heavy crude samples was measured at required temperatures on HAAkE RS 6000
Viscotester. The elemental analyses were performed on German Elementar Vario ELIII analyzer where helium was used as the carrier gas. The heavy crude oil samples were also tested for SARA as per SY/T 5119-2016 standard. During SARA analysis, $n$-hexane was used for deasphalting, and the filtrate was eluted with different organic solvents in the subsequent separation for obtaining saturates, aromatics and resins, respectively.

Fourier transform infrared spectroscopy (FT-IR) analyses of the oil samples were performed using Nicolet iS 10 spectrometer. The samples were scanned in the wavenumber range of $400-4000 \mathrm{~cm}^{-1}$ to record FT-IR spectra.

Gas chromatography (GC) was performed as per SY/T 5779-2008 standard on Agilent $6890 \mathrm{~N}$ with HP5 GC columns and flame ionization detector (FID). Helium was used as the carrier gas at the flow rate of $30 \mathrm{ml} / \mathrm{min}$.

\section{Experimental}

The aquathermolysis experiments were carried out in a high temperature and high-pressure autoclave system, as is illustrated in Fig. 1. $100 \mathrm{~g}$ of the heavy crude oil and required amount of water, the catalysts were placed in WYF-I type autoclave (manufactured by Haian Petroleum Apparatus Factory) with required settings of temperature and reaction time. The air in the autoclave was displaced by nitrogen gas to establish inert atmosphere, and 4-10 MPa pressure was initiated before heating. The temperature and the pressure in the autoclave were recorded every $10 \mathrm{~min}$ during aquathermolysis reactions.

The samples post-aquathermolysis was analyzed as above-mentioned methods. The viscosity reduction ratio $(\Delta \mu)$ is calculated based on Eq. (1) as below:

$\Delta \mu=100 \% \times\left(\mu_{o}-\mu\right) / \mu_{o}$

where $\mu_{o}$ is the initial viscosity of the heavy crude oil, and $\mu$ is the viscosity post-aquathermolysis.

\section{Results and discussion}

\section{Properties of the heavy crude oil}

The properties of the original heavy crude oil are presented in Table 1, and the separation of SARA photographs is shown in Fig. 2. Resins and asphaltenes account for a large proportion in weight fraction. The oil sample was typically characterized by highest content of resins, low content of sulfur and low atomic $\mathrm{H} / \mathrm{C}$ ratio.

The viscosity of the heavy oil is highly temperaturedependent and thus is measured at various temperatures. 
Fig. 1 The autoclave set-up for aquathermolysis

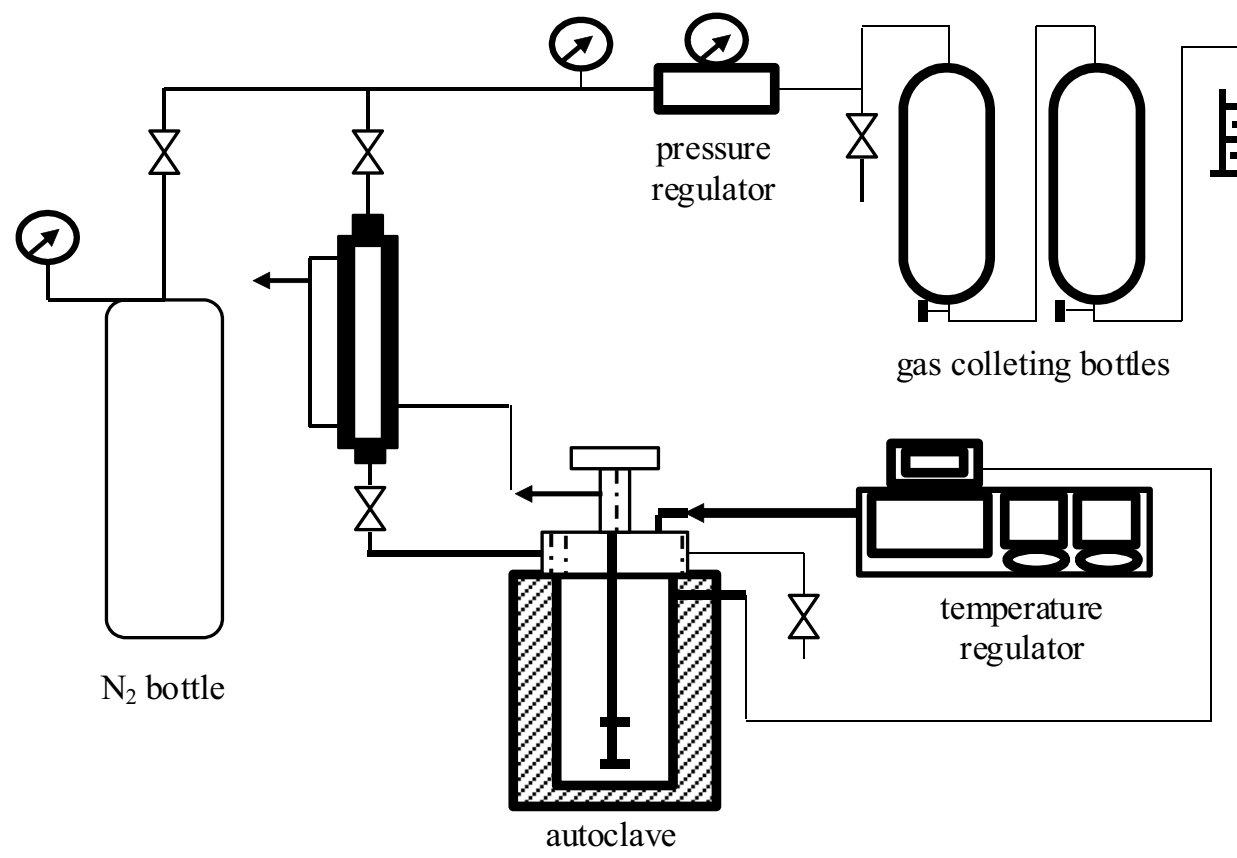

Table 1 The properties of the heavy crude oil

\begin{tabular}{|c|c|c|c|c|c|}
\hline \multicolumn{6}{|c|}{ SARA analysis } \\
\hline $\begin{array}{l}\mu_{\mathrm{o}} \text { at } 50^{\circ} \mathrm{C} \\
(\mathrm{Pa} \cdot \mathrm{s})\end{array}$ & Average molecular weight & $\begin{array}{l}\text { Saturates } \\
\text { (wt\%) }\end{array}$ & $\begin{array}{l}\text { Aromatics } \\
(\mathrm{wt} \%)\end{array}$ & $\begin{array}{l}\text { Resins } \\
\text { (wt\%) }\end{array}$ & $\begin{array}{l}\text { Asphaltenes } \\
\text { (wt\%) }\end{array}$ \\
\hline 183 & 647 & 19.41 & 20.69 & 40.03 & 19.87 \\
\hline \multicolumn{6}{|c|}{ Elemental analysis } \\
\hline $\mathrm{C}(\mathrm{wt} \%)$ & $\mathrm{H}(\mathrm{wt} \%)$ & $\mathrm{S}(\mathrm{wt} \%)$ & $\mathrm{O}(\mathrm{wt} \%)$ & $\mathrm{N}(\mathrm{wt} \%)$ & atom $\mathrm{H} / \mathrm{C}$ ratio \\
\hline 83.59 & 11.21 & 2.72 & 0.77 & 0.87 & 1.60 \\
\hline
\end{tabular}

The $\mu_{\mathrm{o}}-t$ relationship fitting curve is presented in Fig. 3. It conforms to Eq. (2) as below:

$\mu_{o}=6891.86216 \cdot \exp (-0.07248 t)$

where $\mu_{\mathrm{o}}$ represents the viscosity in Pa.s, and $t$ is the temperature in Celsius degree. Correlation coefficient $R^{2}$ (0.99199) is close to 1.0 , demonstrating a good fitting result.

\section{Characterization of the submicro-catalysts}

The purity and the crystalline structure of the submicro-transition metal oxides were examined by X-ray powder diffraction (XRD) using RINT2000 vertical goniometer with standard sample holder and fixed monochromator. $\mathrm{Cu} k-\alpha_{1}(40 \mathrm{kV}$, $40 \mathrm{~mA}$ ) was employed for continuous scanning in the 2-theta range from $20^{\circ}$ to $70^{\circ}$ with 0.02 step and $1^{\circ}$ DivSlit. The XRD patterns of the transition metal oxides submicro-particles are shown in Fig. 4. The diffraction peaks in terms of the peak positions and the relative intensity are matching the standard spectrum of $\mathrm{NiO}$ (PDF\#44-1159), $\alpha \cdot \mathrm{Fe}_{2} \mathrm{O}_{3}$ (PDF\#80-2377) and $\mathrm{Co}_{3} \mathrm{O}_{4}$ (PDF\#42-1467), respectively. The purity of the samples was verified as single phase from the characteristic peaks of the XRD patterns.

Since the average particle size of each sample calculated by Scherrer formula is over $100 \mathrm{~nm}$ (generally considered as the critical size that defines whether Scherrer formula should be employed), the microstructure of the samples was also examined with scanning electron microscopy (SEM) using Quanta FEG450, as is shown in Fig. 5. The size distribution of the transition metal oxides submicro-particles demonstrates that the average size of $\mathrm{NiO} / \alpha \cdot \mathrm{Fe}_{2} \mathrm{O}_{3} / \mathrm{Co}_{3} \mathrm{O}_{4}$ is $118.1 \mathrm{~nm} / 245.0 \mathrm{~nm} / 268.7 \mathrm{~nm}$, respectively.

\section{Influential factors on aquathermolysis}

As is well-known, aquathermolysis is essentially the breakage of the weak chemical bonds which requires certain 
Fig. 2 The photographs of SARA
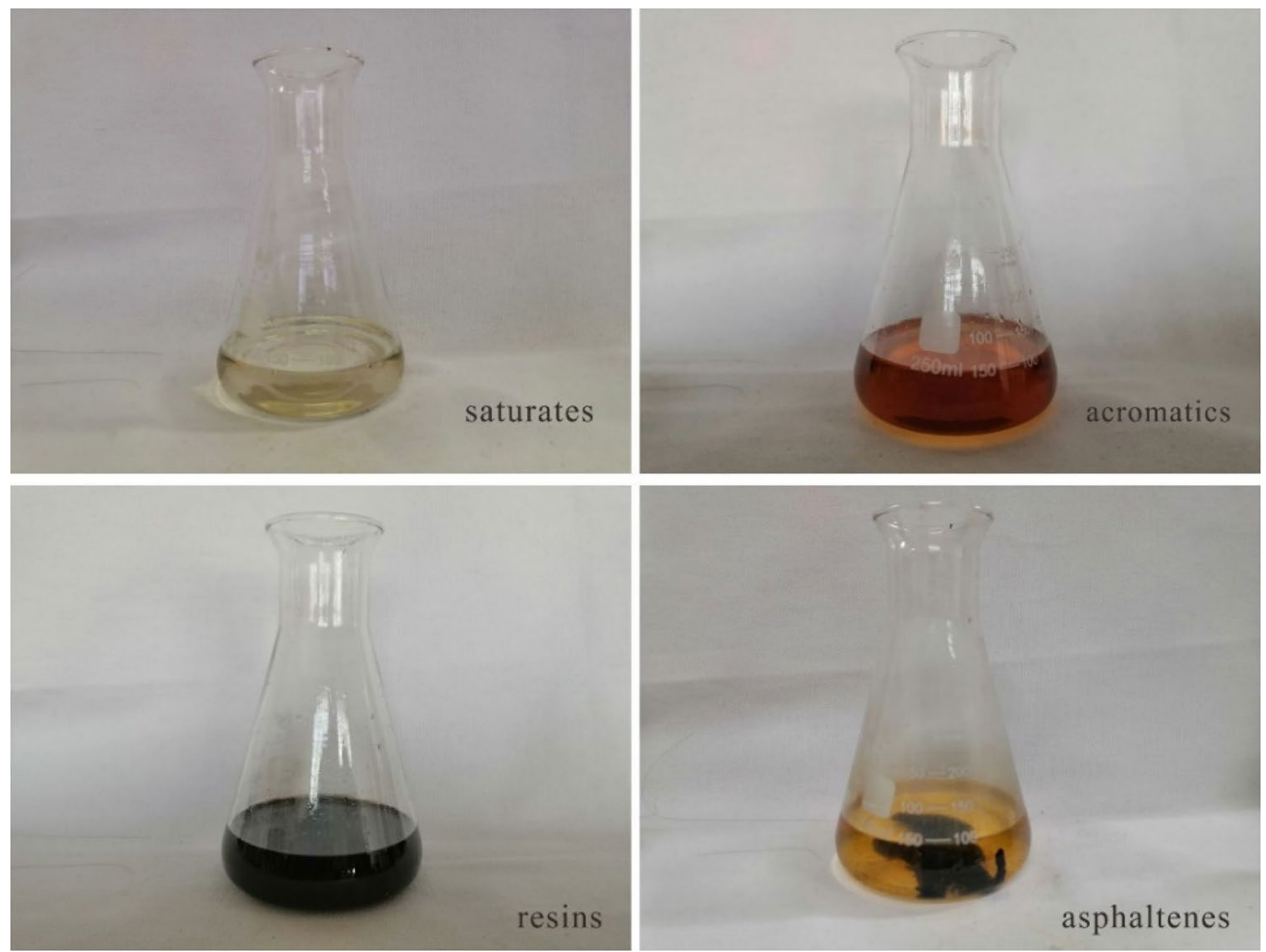

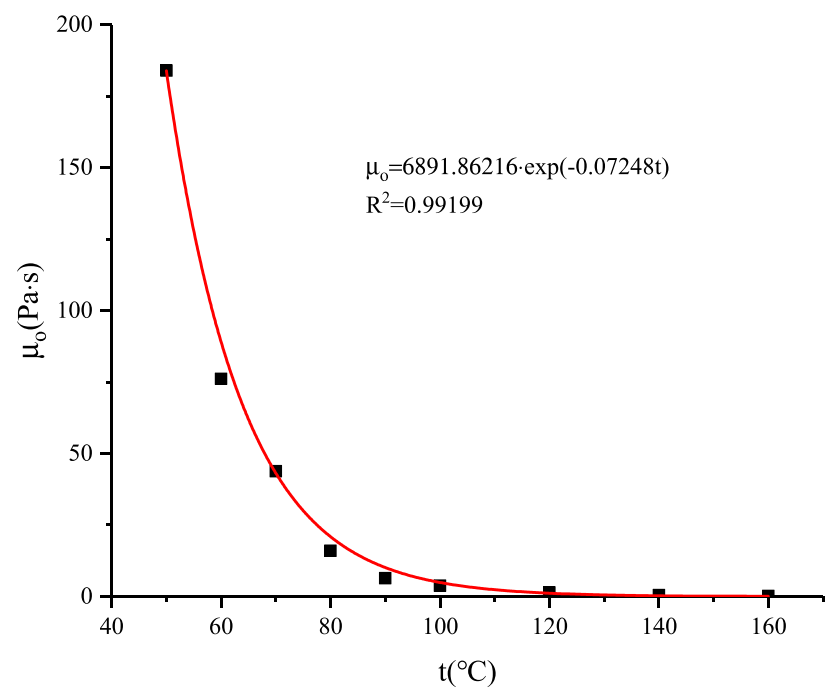

Fig. 3 The relationship curve of oil viscosity $\left(\mu_{\mathrm{o}}\right)$ and temperature $(t)$

amount of energy. During steam injection processes, the injection temperature of the steam is higher than $300{ }^{\circ} \mathrm{C}$, and the reservoirs can be heated up to $200^{\circ} \mathrm{C}$ and higher. Therefore, the temperature range in the experiments was set from 180 to $300{ }^{\circ} \mathrm{C}$. The influence of experimental parameters, including reaction temperature, catalyst usage, mass fraction of water and reaction time, was evaluated by analyzing viscosity reduction, as is illustrated in Fig. 6.

Elevation of reaction temperature resulted in viscosity reduction. When reaction temperature was below

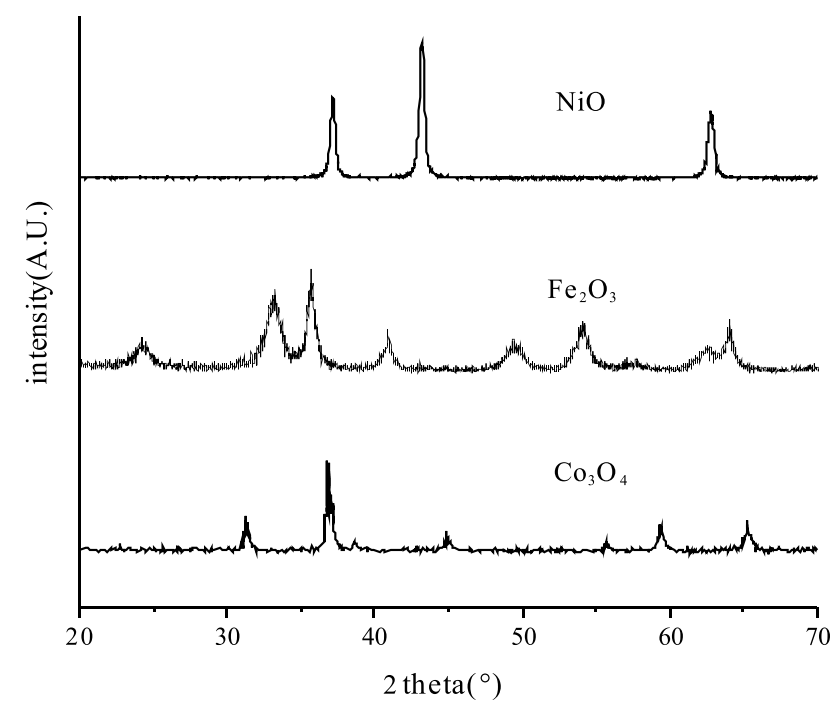

Fig. 4 XRD patterns of the transition metal oxides submicro-particles

$240{ }^{\circ} \mathrm{C}$, viscosity reduction was enhanced tremendously. The temperature was elevated above $240{ }^{\circ} \mathrm{C}$, the extent of viscosity reduction became small, and the trend tended to be steady. This indicated that aquathermolysis was approaching to the end at the temperature. It was also noticed that the viscosity was reduced further at $300{ }^{\circ} \mathrm{C}$ characterized by an upsurge in the curve. This was caused by thermal pyrolysis at the relatively high temperature. Considering the actual process of steam injection, $240{ }^{\circ} \mathrm{C}$ 

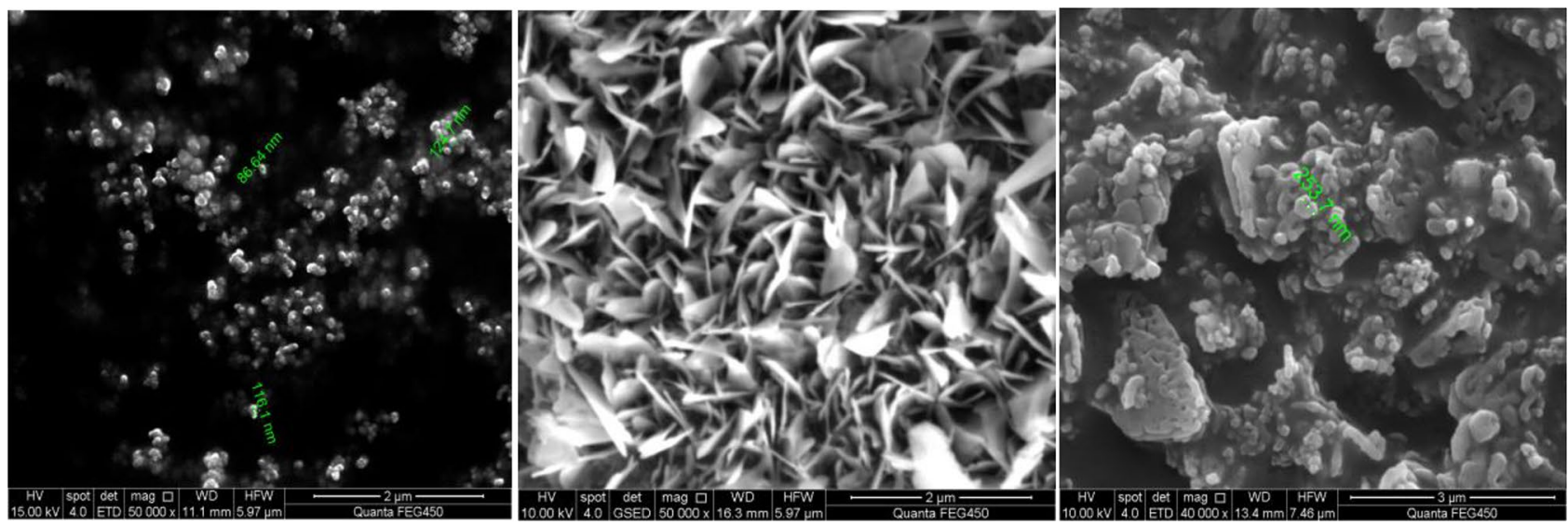

Fig. 5 SEM images of the transition metal oxides submicro-particles
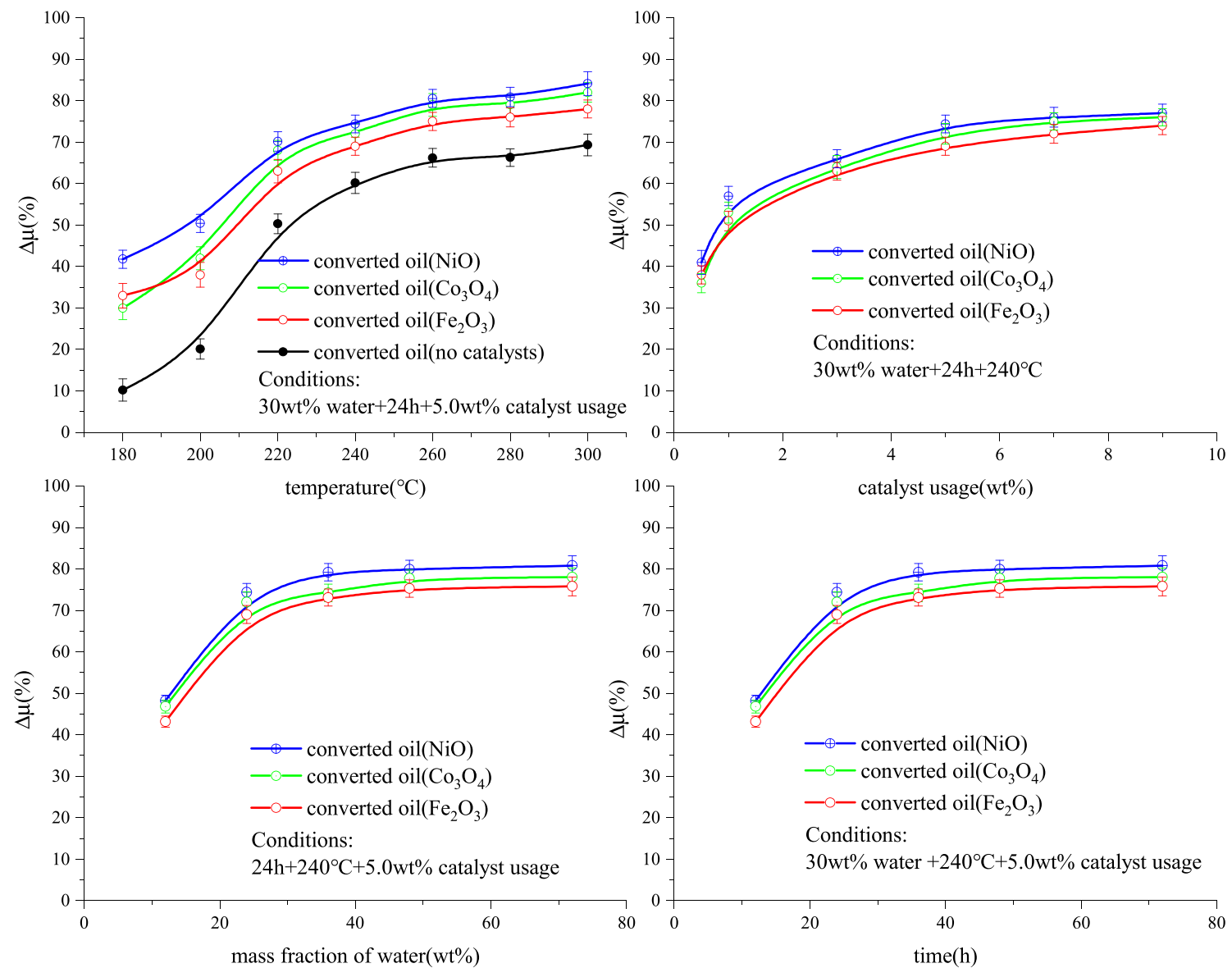

Fig. 6 Influence of operating parameters on $\Delta \mu$ with different catalysts

can be regarded as the optimum reaction temperature for aquathermolysis. Considering the operational applicability and the cost of the catalysts, the aquathermolysis approached toward the optimum state with $30 \mathrm{wt} \%$ mass fraction of water, $5.0 \mathrm{wt} \%$ catalyst usage and $24 \mathrm{~h}$ ' reaction time. The greatest catalytic activity was noticed in the presence of $\mathrm{NiO}$, where oil viscosity was significantly decreased by $74.38 \%$. 


\section{Oil properties analysis}

The variation of SARA post-aquathermolysis $\left(240{ }^{\circ} \mathrm{C}, 24 \mathrm{~h}\right.$ and $5.0 \mathrm{wt} \%$ catalyst usage) was examined and illustrated in Fig. 7. Compared to initial oil, aquathermolysis led to increase in saturates by $2.91 \mathrm{wt} \%$ and aromatics by $2.83 \mathrm{wt} \%$ and decrease in resins by $3.45 \mathrm{wt} \%$ and asphaltenes by $2.29 \mathrm{wt} \%$. The enhancement was observed by addition of transition metal oxides microparticles. $\mathrm{NiO}$ also presented greatest catalytic effect on SARA variation during aquathermolysis, where saturates and aromatics increased by $8.01 \mathrm{wt} \%$ and $9.82 \mathrm{wt} \%$, resins and asphaltenes decreased by $9.22 \mathrm{wt} \%$ and $8.61 \mathrm{wt} \%$, respectively. The breakage of $\mathrm{C}-\mathrm{S}$ bonds, $\mathrm{C}-\mathrm{N}$ bonds and $\mathrm{C}-\mathrm{O}$ bonds is the basic forms of thermal cracking during aquathermolysis, and these heteroatoms are primarily present in the heavy components (e.g., resins and asphaltenes) of the crude oil. Therefore, aquathermolysis resulted in increase in saturates and aromatics and decrease in resins and asphaltenes.

Elemental analyses were conducted, and the result is shown in Table 2. The content of carbon and heteroatoms decreased, while hydrogen content increased, leading to the increase of $\mathrm{H} / \mathrm{C}$ atomic ratio. Among these heteroatoms, the content of sulfur element decreased to the greatest extent in the presence of $\mathrm{NiO}$ submicro-particles, which proves that desulfurization is one of the most dominating reactions for oil viscosity reduction and $\mathrm{NiO}$ effectively accelerates the aquathermolysis.

FT-IR analyses were carried out using the initial oil, converted oil by aquathermolysis $\left(240^{\circ} \mathrm{C}+24 \mathrm{~h}+30 \mathrm{wt} \%\right.$ water) and converted oil by catalytic aquathermolysis $(5.0 \mathrm{wt} \% \mathrm{NiO})$. The result is shown in Fig. 8. The FT-IR spectra of the initial oil exhibited absorptions at $2850 \mathrm{~cm}^{-1}$ and $2920 \mathrm{~cm}^{-1}$ (naphthene and C-H stretching), $1707 \mathrm{~cm}^{-1}(\mathrm{C}=\mathrm{O}$ stretching $), 1457 \mathrm{~cm}^{-1}$ and $1377 \mathrm{~cm}^{-1}\left(\mathrm{C}-\mathrm{CH}_{3}\right.$ unsymmetrical and $-\mathrm{CH}_{2}-$ symmetrical stretching). The characteristic FT-IR absorptions at $3450 \mathrm{~cm}^{-1}$ related to $\mathrm{O}-\mathrm{H}$ stretching had weakened after aquathermolysis reactions. This may be caused by olefinic alcohol hydrolysis, aldehyde decomposition and water gas shift reaction (WGSR). After catalytic aquathermolysis, the characteristic FT-IR absorptions near $1610 \mathrm{~cm}^{-1}$ were strengthened, indicating the reduction in aromatic ring number. Heteroatoms (e.g., S, O, N) are normally situated on condensed rings in the heavy crude oil. Hydrogenation and de-heteroatoms effects during aquathermolysis contributed to the reduction in aromatic ring number.
Fig. 7 Variation in SARA fractions at $240{ }^{\circ} \mathrm{C}$ under different conditions
Table 2 Elemental analysis preand post-aquathermolysis

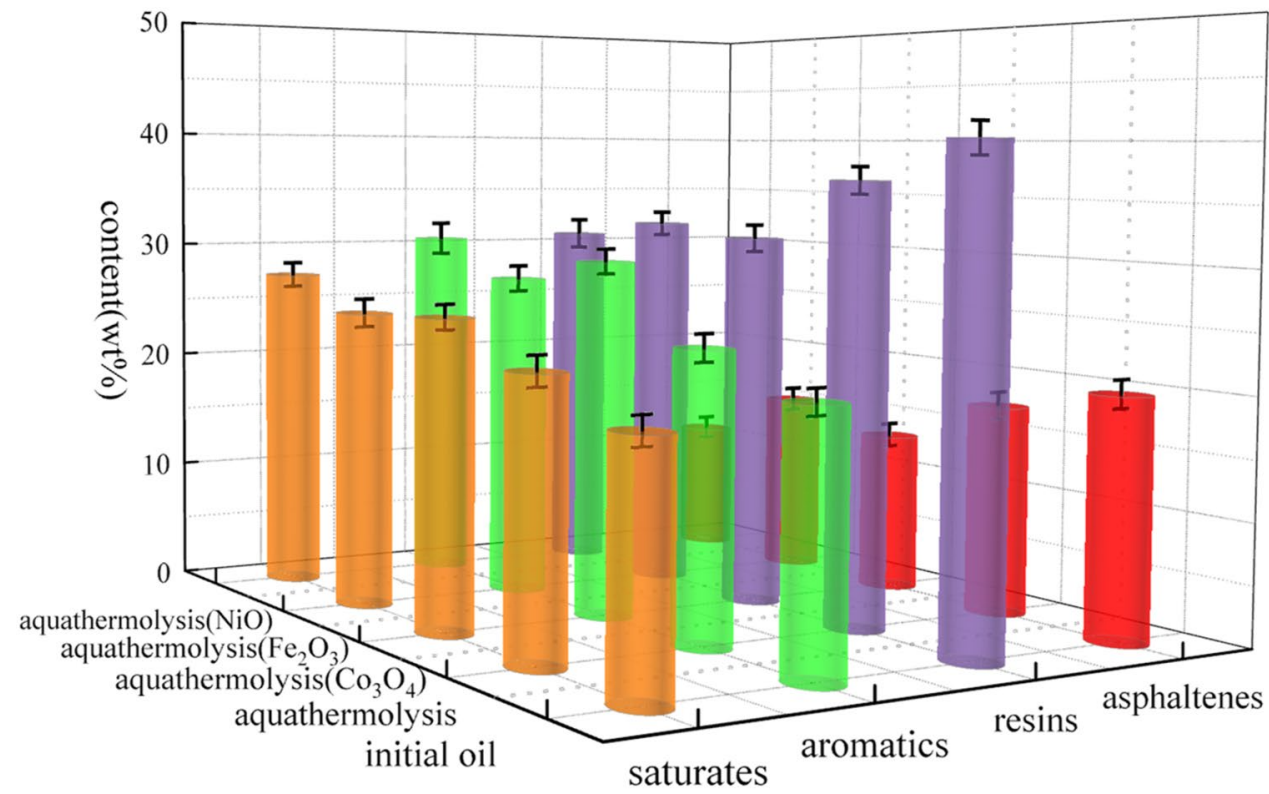

\begin{tabular}{lllllll}
\hline Reaction & $\mathrm{C}(\mathrm{wt} \%)$ & $\mathrm{H}(\mathrm{wt} \%)$ & $\mathrm{S}(\mathrm{wt} \%)$ & $\mathrm{O}(\mathrm{wt} \%)$ & $\mathrm{N}(\mathrm{wt} \%)$ & $\begin{array}{l}\text { atomic } \\
\mathrm{H} / \mathrm{C} \\
\text { ratio }\end{array}$ \\
\hline Initial & 83.59 & 11.21 & 2.72 & 0.77 & 0.87 & 1.60 \\
Aquathermolysis & 83.18 & 11.71 & 2.09 & 0.68 & 0.79 & 1.69 \\
NiO+ aquathermolysis & 82.93 & 12.62 & 1.24 & 0.45 & 0.63 & 1.79 \\
\hline
\end{tabular}




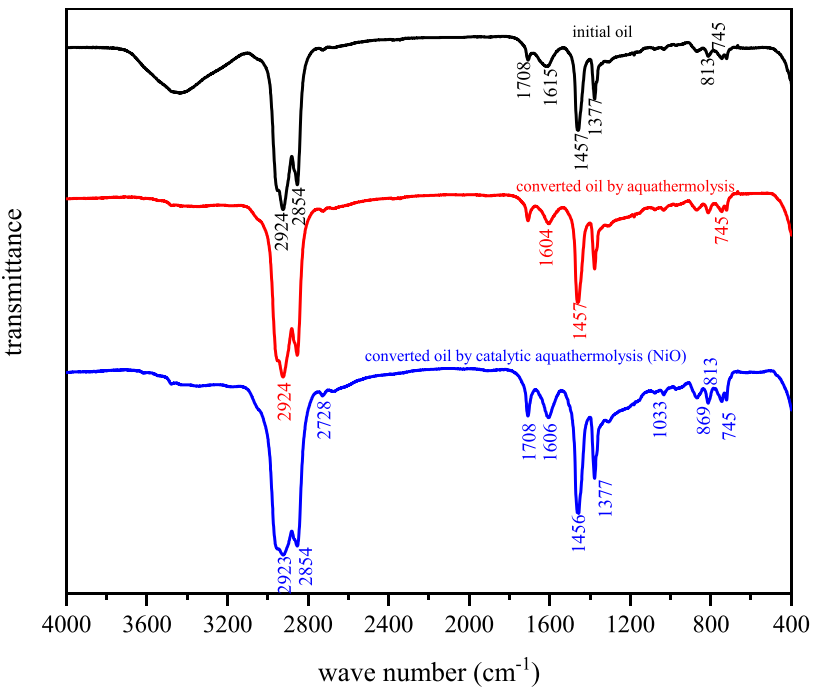

Fig. 8 FT-IR of the heavy oils pre- and post-aquathermolysis

A gas chromatograph where components of initial oil, converted oil by aquathermolysis $\left(240{ }^{\circ} \mathrm{C}+24 \mathrm{~h}+30 \mathrm{wt} \%\right.$ water) and converted oil by catalytic aquathermolysis (addition of $5.0 \mathrm{wt} \% \mathrm{NiO}$ ) were separated via a separation column and signals were recorded, as is shown in Fig. 9. There appear the peaks of $\mathrm{C}_{6}-\mathrm{C}_{9}$ after aquathermolysis and $\mathrm{C}_{5}-\mathrm{C}_{10}$ after catalytic aquathermolysis. Light hydrocarbons increase and heavy hydrocarbons increase after aquathermolysis. When the catalyst is added to the reaction system, light hydrocarbons $\left(<\mathrm{C}_{10}\right)$ further increase by $2.91 \%$ and heavy hydrocarbons $\left(>\mathrm{C}_{25}\right)$ decrease by $8.73 \%$.

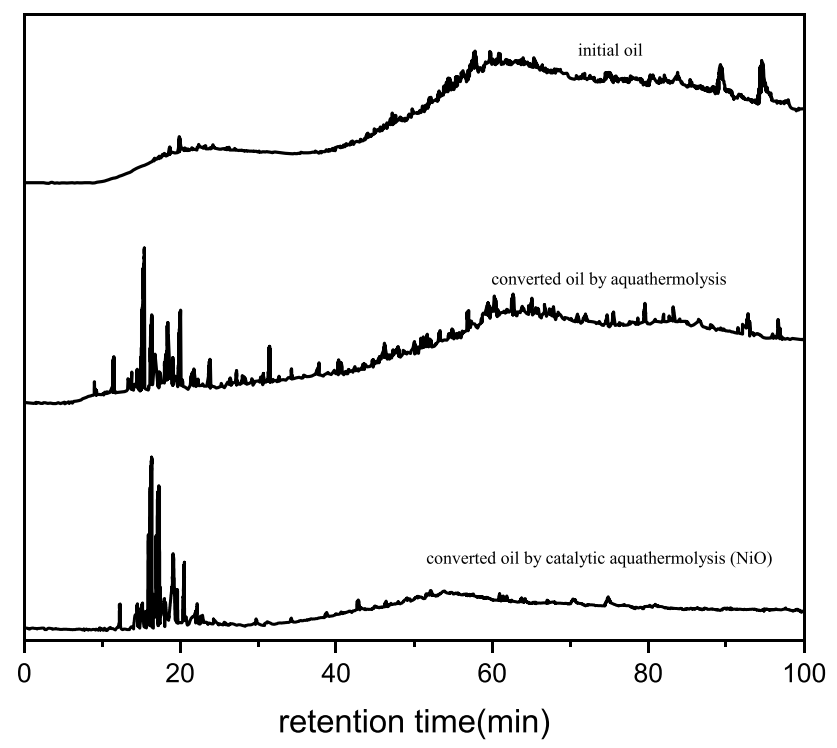

Fig. 9 Gas chromatograph of the heavy oils pre- and post-aquathermolysis

\section{Kinetics of aquathermolysis}

Breakage of carbon-sulfur bond is significant in aquathermolysis, resulting in conversion of large molecules to multiple small molecules. The contents of heteroatoms decrease in the order of asphaltenes, resins, aromatics and saturates in heavy oils. Therefore, a five-lump kinetic model is established to involve asphaltenes, resins, aromatics and saturates, and gases are also added to the model to accurately describe the aquathermolysis reaction processes. The reaction scheme of the proposed five lumps kinetic model for aquathermolysis is shown in Fig. 10.

The kinetic parameters of aquathermolysis including activation energy and pre-exponential factor are associated with the rate and the degree of the reaction. Based upon the assumption of first-order reaction, the aquathermolysis processes are described as follows:

$\frac{\mathrm{d} x_{1}}{\mathrm{~d} t}=-\left(k_{1}+k_{11}+k_{10}\right) x_{1}+k_{2} x_{2}$

$\frac{\mathrm{d} x_{2}}{\mathrm{~d} t}=-\left(k_{2}+k_{3}+k_{5}+k_{7}\right) x_{2}+k_{1} x_{1}+k_{3} x_{3}$

$\frac{\mathrm{d} x_{3}}{\mathrm{~d} t}=-\left(k_{4}+k_{8}+k_{9}\right) x_{3}+k_{3} x_{2}$

$\frac{\mathrm{d} x_{4}}{\mathrm{~d} t}=-k_{6} x_{4}+k_{10} x_{1}+k_{5} x_{2}+k_{8} x_{3}$

$\frac{\mathrm{d} x_{5}}{\mathrm{~d} t}=k_{11} x_{1}+k_{7} x_{2}+k_{9} x_{3}+k_{6} x_{4}$

The mathematical relationship between absolute temperature and the rate of the chemical reactions follows Arrhenius equation:

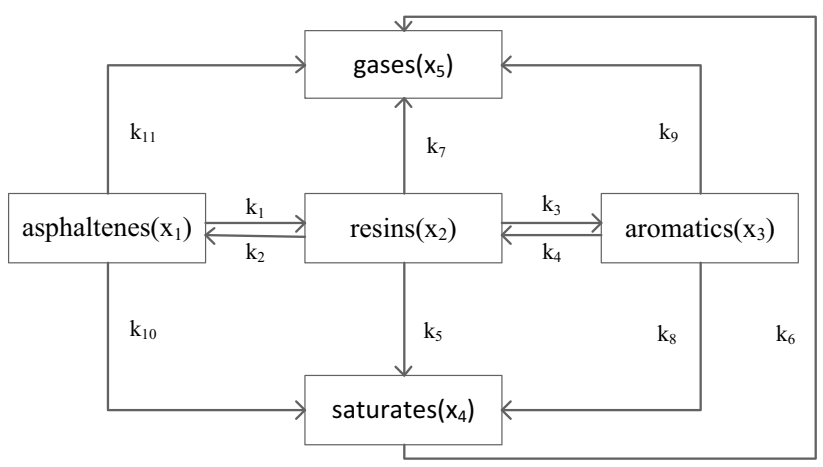

Fig. 10 Proposed reaction scheme of aquathermolysis for the five lumps kinetic model 
Table 3 Estimated kinetic parameters of proposed five lumps kinetic model

\begin{tabular}{llllllr}
\hline$k\left(\mathrm{~h}^{-1}\right)$ & $200{ }^{\circ} \mathrm{C}$ & $220{ }^{\circ} \mathrm{C}$ & $240^{\circ} \mathrm{C}$ & $260{ }^{\circ} \mathrm{C}$ & $A\left(h^{-1}\right)$ & $E(\mathrm{~kJ} / \mathrm{mol})$ \\
\hline$k_{1}$ & 0.0158 & 0.0886 & 0.6171 & 0.8152 & $6.11 \times 10^{10}$ & 145.4477 \\
$k_{2}$ & 0.0057 & 0.0527 & 0.5562 & 0.8232 & $2.83 \times 10^{14}$ & 182.3933 \\
$k_{3}$ & 0.0141 & 0.0817 & 0.1854 & 0.2666 & $9.94 \times 10^{5}$ & 102.0378 \\
$k_{4}$ & 0.0139 & 0.0841 & 0.1971 & 0.2819 & $1.98 \times 10^{6}$ & 104.7947 \\
$k_{5}$ & $2.7 \times 10^{-9}$ & $1.10 \times 10^{-8}$ & $9.0 \times 10^{-8}$ & $1.54 \times 10^{-7}$ & $2.79 \times 10^{4}$ & 149.9427 \\
$k_{6}$ & $2.63 \times 10^{-6}$ & $8.47 \times 10^{-6}$ & $2.26 \times 10^{-5}$ & $4.16 \times 10^{-5}$ & $4.60 \times 10^{2}$ & 97.4601 \\
$k_{7}$ & $2.56 \times 10^{-9}$ & $1.58 \times 10^{-8}$ & $9.31 \times 10^{-8}$ & $1.12 \times 10^{-7}$ & $1.96 \times 10^{3}$ & 138.8278 \\
$k_{8}$ & 0.0046 & 0.0091 & 0.0485 & 0.0881 & $1.69 \times 10^{6}$ & 110.2795 \\
$k_{9}$ & $4.27 \times 10^{-6}$ & $1.07 \times 10^{-5}$ & $5.58 \times 10^{-5}$ & $8.05 \times 10^{-5}$ & $1.64 \times 10^{3}$ & 109.9909 \\
$k_{10}$ & $1.0 \times 10^{-12}$ & $7.41 \times 10^{-11}$ & $1.75 \times 10^{-10}$ & $2.66 \times 10^{-9}$ & $1.61 \times 10^{13}$ & 258.2649 \\
$k_{11}$ & $8.93 \times 10^{-8}$ & $1.95 \times 10^{-7}$ & $1.25 \times 10^{-6}$ & $1.71 \times 10^{-5}$ & $2.53 \times 10^{9}$ & 183.1869 \\
\hline
\end{tabular}

$k_{i}=A \cdot \exp \left(-E_{i} / R T\right)$

The comparison between the experimentally measured data and the calculated results is given in Fig. 11. The dots are the experimentally measured data, and the solid lines are the theoretically calculated results. As is seen, the calculated results agree with the experimental data, indicating the proposed five-lump model is fit for purpose in terms of estimating kinetic parameters of aquathermolysis.

\section{Conclusions}

Based upon the experiments and the results from the literature, some resins and asphaltenes were consumed and converted to saturates and resins and other byproducts such as $\mathrm{H}_{2}, \mathrm{CO}_{2}, \mathrm{CO}, \mathrm{H}_{2} \mathrm{~S}, \mathrm{CH}_{4}$ during aquathermolysis. The FT-IR, GC and viscosity/SARA/elemental analysis results demonstrate in situ upgrading of the heavy crude oil. The catalyst $\mathrm{NiO}$ was selected to enhance aquathermolysis, and the optimum mass fraction was determined experimentally. The addition of the catalyst is beneficial to field implementation in relation to steam injection when designed properly. A five-lump model is proposed for estimating kinetic parameters of aquathermolysis and agrees well with the experimental data. 

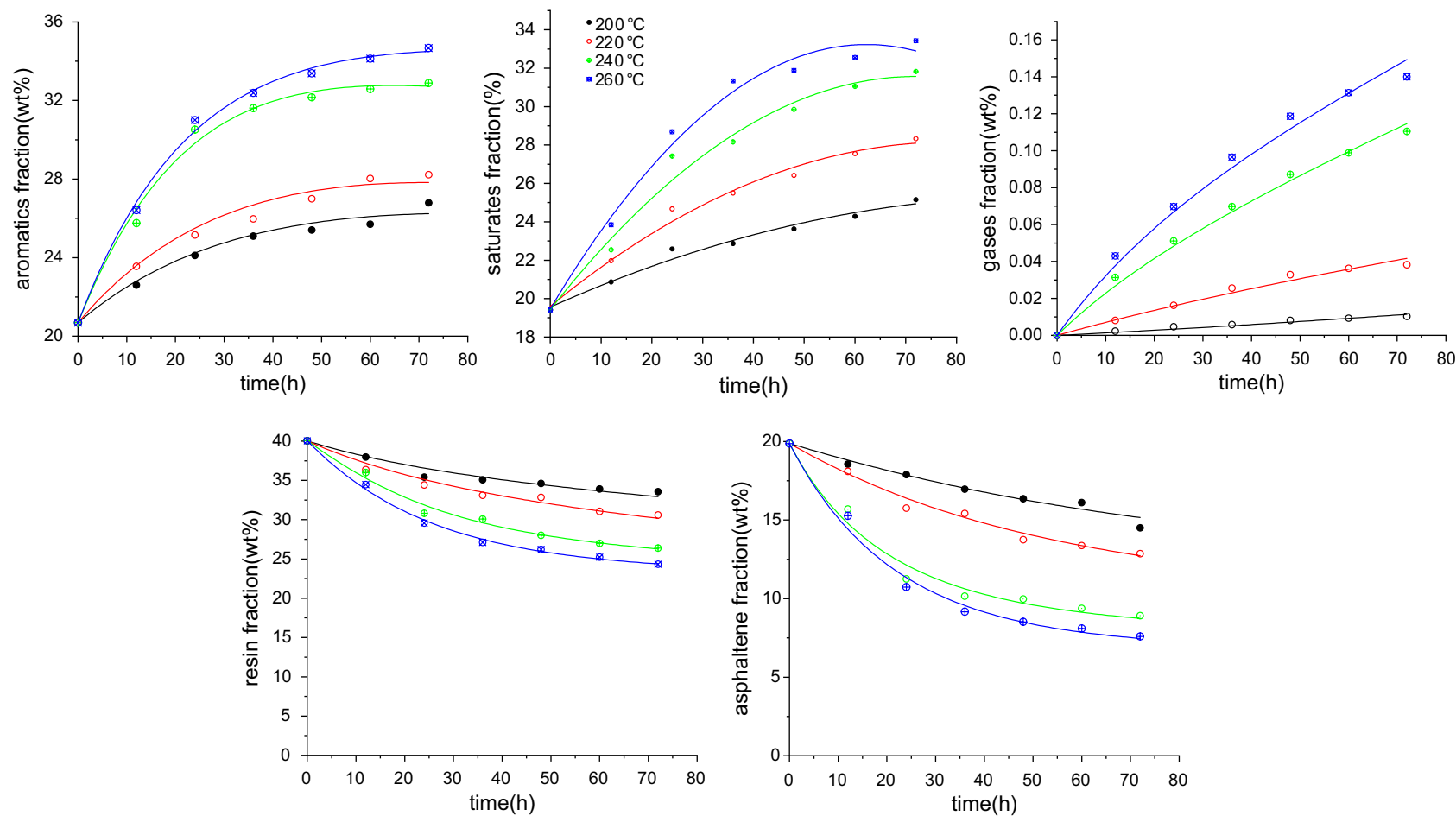

Fig. 11 Degree of agreement of calculated results with experimental data

Acknowledgements This work was supported by National Natural Science Foundation of China [51904076] and NEPU youth nursing program for Natural Science Fund [2018GPQZ-04].

Funding This work was financially supported by National Natural Science Foundation of China [51904076] and NEPU youth nursing program for Natural Science Fund [2018GPQZ-04].

\section{Declarations}

Conflict of interest On behalf of all the co-authors, the corresponding author states that there is no conflict of interest.

Open Access This article is licensed under a Creative Commons Attribution 4.0 International License, which permits use, sharing, adaptation, distribution and reproduction in any medium or format, as long as you give appropriate credit to the original author(s) and the source, provide a link to the Creative Commons licence, and indicate if changes were made. The images or other third party material in this article are included in the article's Creative Commons licence, unless indicated otherwise in a credit line to the material. If material is not included in the article's Creative Commons licence and your intended use is not permitted by statutory regulation or exceeds the permitted use, you will need to obtain permission directly from the copyright holder. To view a copy of this licence, visit http://creativecommons.org/licenses/by/4.0/.

\section{References}

Anderson W, Kozak D, Coleman VA, Jämting AK, Trau M (2013) A comparative study of submicron particle sizing platforms: accuracy, precision and resolution analysis of polydisperse particle size distributions. J Coll Interface Sci 405:322-330. https://doi.org/10. 1016/j.jcis.2013.02.030

Burrage K, Burrage PM (2000) Order conditions of stochastic RungeKutta methods by B series. SIAM J Numer Anal 38(5):16261646. https://doi.org/10.1137/S0036142999363206

Clark PD, Hyne JB (1984) Steam-oil chemical reactions: mechanism for the aquathermolysis of heavy oils. Aostra J Res 1(1):15-20

Chen M, Li C, Li G, Chen Y, Zhou C (2019) In situ preparation of well-dispersed $\mathrm{CuO}$ nanocatalysts in heavy oil for catalytic aquathermolysis. Pet Sci 16:439-446. https://doi.org/10.1007/ s12182-019-0300-3

Galukhin AV, Khelkhal MA, Eskin AV, Osin YN (2017) Catalytic combustion of heavy oil in the presence of manganese-based submicro particles in a quartz porous medium. Energy Fuels 31(10):1125311257. https://doi.org/10.1021/acs.energyfuels.7b01856

Huang SJ, Huang Q, Liu H, Cheng LS, Fan ZF, Zhao L (2017) A modified model for aquathermolysis and its application in numerical simulation. Fuel 207:568-578. https://doi.org/10.1016/j.fuel. 2017.06.127

Iskandar F, Dwinanto E, Abdullah M, Muraza KO (2016) Viscosity reduction of heavy oil using nanocatalyst in aquathermolysis reaction. Kona Powder Part J 33:3-16

Kapadia PR, Kallos MS, Gates ID (2012) A new reaction model for aquathermolysis of Athabasca bitumen. Can J Chem Eng 9999:18. https://doi.org/10.1002/cjce.21662

Kapadia PR, Kallos MS, Gates ID (2015) A review of pyrolysis, aquathermolysis, and oxidation of Athabasca bitumen. Fuel

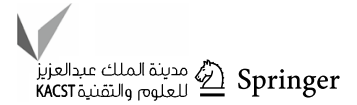


Process Technol 131:270-289. https://doi.org/10.1016/j.fuproc. 2014.11.027

Liu C, Liu Y, Chen X (2004) Kinetic study on aquathermolysis reaction of viscous oil. Chem Eng Oil Gas 33(4):281-283

Lakhova A, Petrov S, Ibragimova D, Kayukova G, Safiulina A, Shinkarev A, Okekwe R (2017) Aquathermolysis of heavy oil using nano oxides of metals. J Pet Sci Eng 153:385-390. https://doi.org/10. 1016/j.petrol.2017.02.015

Li Y, Li Q, Wang X, Yu L, Yang Y (2018a) Aquathermolysis of heavy crude oil with ferric oleate catalyst. Pet Sci 15:613-624. https:// doi.org/10.1007/s12182-018-0246-X

Li T, Xu J, Zou R, Feng H, Li L, Wang J, Martien A, Stuart C, Guo X (2018b) Resin from Liaohe heavy oil: molecular structure, aggregation behavior, and effect on oil viscosity. Energy Fuels 32(1):306-313. https://doi.org/10.1021/acs.energyfuels.7b03279

Muraza O, Galadimaa A (2015) Aquathermolysis of heavy oil: a review and perspective on catalyst development. Fuel 157(1):219-231. https://doi.org/10.1016/j.fuel.2015.04.065
Perez-Perez A, Kamp AM, Soleimani H, Darche G (2011) Numerical simulation of $\mathrm{H}_{2} \mathrm{~S}$ and $\mathrm{CO}_{2}$ generation during SAGD. World Heavy Oil Congress, Edmonton, Alberta, Canada, 14-17 March.

Santos RG, Loh W, Bannwart AC, Trevisan OV (2014) An overview of heavy oil properties and its recovery and transportation methods. Braz J Chem Eng 31(3):571-590. https://doi.org/10.1590/01046632.20140313s00001853

Yi Y, Li S, Ding F, Yu H (2009) Change of asphaltene and resin properties after catalytic aquathermolysis. Pet Sci 6:194-200. https:// doi.org/10.1007/s12182-009-0031-y

Zhang X, Liu Y, Fan Y, Che H (2010) Effects of reservoir minerals and chemical agents on aquathermolysis of heavy oil during steam injection. Chin Pet Process Petrochem Technol 12(3):25-31

Zhao F, Liu Y, Zhang B, Chen Q (2011) Upgrading heavy oil by catalytic aquathermolysis using formic acid as hydrogen donor. Adv Mater Res 236:844-849

Publisher's Note Springer Nature remains neutral with regard to jurisdictional claims in published maps and institutional affiliations. 